\title{
Experimental Study on Defects Testing of Crane based on $A E$
}

\author{
Zhao Xin ${ }^{1,2}$, Chen Da ${ }^{1, \text { a * }}$, Yang Qiang ${ }^{1}$, and Sun Zhili ${ }^{1}$ \\ ${ }^{1}$ School of Mechanical Engineering \& Automation, Northeastern University, Shenyang 110819, \\ China; \\ ${ }^{2}$ Liaoning Academy of Safety Science, Crane Department, Shenyang 110003, China; \\ a13942741911@163.com
}

Keywords: cranes, AE, detection, Q235, crack, welding defects.

\begin{abstract}
The online location and feature identification of the conventional defects such as cracks is the key to crane safety evaluation and accident prevention. SDAES acoustic emission (AE) detector and GPS-100 high frequency fatigue tensile testing machine are used to collect and analyze the AE signals of specimens of Q235 material, cracks and welding defects under different loading conditions, and then fault location estimation as well as signal and spectral characteristics analysis of conventional defects are achieved by applying signal processing techniques. Finally, the main characteristic parameters distribution ranges are analyzed from the typical AE experimental signal of Q235 material and conventional defects samples. Research in this paper provides basic data and technical reference for the application of AE to crane hazard detection.
\end{abstract}

\section{Introduction}

With the widespread use of crane machines, there is a huge amount of property damages and personal injuries in both foreign and domestic markets. The online location and fault feature identification of hazard sources including crack and welding defects is the key to crane safety evaluation and accident prevention. Due to the complexity of obtaining AE signals in field condition and the lack of typical samples of AE source parameters, the research of crane NDT based on AE is still in the exploratory stage. Kaiser discovered that copper, steel, and metal alloy and metal alloy have AE phenomena in the event of deformation [1]. Javadi Y and Sadeghi S studied the elastic wave propagation characteristics of crane plates, and with the help it's possible to locate linear source [2] .Some researchers describe the damage evolution and failure mechanism of specimens at different failure stages by using the parameters of $\mathrm{AE}$ event number, amplitude, energy and duration $[3,4]$.AE refers to the phenomenon of transient elastic waves generated by the local rapid release of energy. The frequency and amplitude of the AE emitted in different conditions and processes is quite different.AE elastic waves can reflect some physical properties and damage of materials or components. Therefore, the method of detecting AE signals can be used to judge the state of machine. In order to locate the defect position on the material surface, several sensors should be placed on the fixed point according to certain geometric relations. The position of the AE source is determined by the AE signal detected by sensors, this method is called source localization. 


\section{Experiment}

To solve the problem of the conventional defect detection of the crane, we design an AE experiment containing the Q235 specimen of the non-crack, crack and the welding defect. We use the signal analysis technique to analyze the defects, parameters and the wave characteristics. The results indicate that the $\mathrm{AE}$ technology is effective in detecting and evaluating crane operating status.

\subsection{Specimen preparation}

The tensile specimens are divided into three types, which are non-defect, crack defects and welding defects specimen. To explore different acoustic signatures in the same size specifications. At the center of the specimen, we have made a crack which is $5 \mathrm{~mm}$ wide, $1 \mathrm{~mm}$ deep and through the entire specimen. The welding defect specimen (Fig.1) are prefabricated with type I slope, which is $2 \mathrm{~mm}$ wide and through the entire specimen.

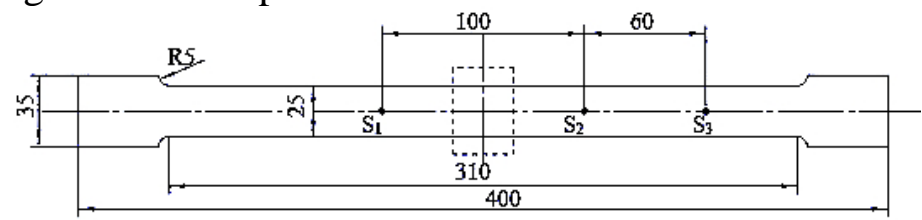

Fig. 1 Q235A dimensions of defect free tensile specimens

\subsection{Experimental equipment}

We use GPS-100 high frequency fatigue tensile testing machine to implement the test load anddetect AE signals by SDAES AE detector made by Soundwell.corp.

\subsection{Experimental system}

The whole test system consists of hardware and software systems(Fig.2).

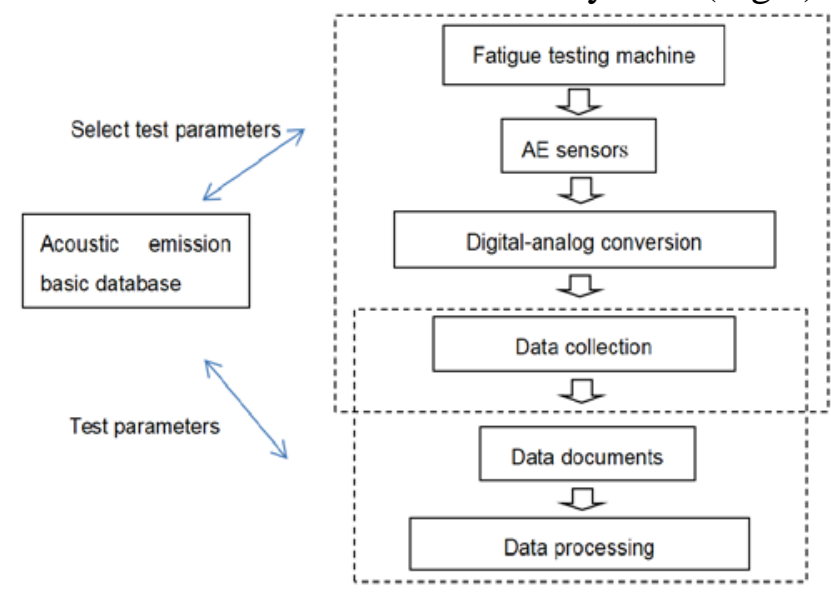

Fig.2 Architecture and principles of the test system

\subsection{Layout of the sensor}

For all the three types of specimens, three sensors S1,S2,S3 were used to form one-dimensional linear localization (Fig. 1). AE detection was carried out on the specimens to record AE signals. 


\section{Results}

\subsection{Analysis of AE parameters in tensile process of cracked Q235 specimen}

The location analysis in Table 1 is a statistical table of AE events during four load processes

Table 1 AE positioning event statics of specimen loading process

\begin{tabular}{ccccc}
\hline steps & loading $(\mathrm{kN})$ & Main location position $(\mathrm{mm})$ & Number of events & note \\
\hline 1st & $6-10$ & 40 & 8 & Flawed position \\
2st & $10-15$ & 40 & 4 & Flawed position \\
3st & $15-20$ & 40 & 5 & Flawed position \\
4st & $20-27.86$ & $40,72,86,118$ & 7 & Dispersed distribution \\
\hline
\end{tabular}

As shown in table 1, of all 24 finally calculated localization points, 10 registration points are located at the crack defect point, which is the main location concentration area. Other location have a wide range of distribution. It can be seen from table 1 that the AE linear localization method can be used to accurately locate the crack defects of specimens.

The counts, Energy, history Amplitude and Hits diagram shows the characteristic parameters of AE signal of crack growth during the process of loading. The counts, energy and hits distribution are distributed uniformly, while the distribution of amplitudes occurs in two central areas, near 40 $\mathrm{db}$ and $54 \mathrm{db}$ respectively. Analysis shows that the peak value near $40 \mathrm{~dB}$ is caused by the residual stress of the specimen, the friction between the specimen surface and the fixture, and the signal generated by the weak dislocation motion in the material; The signal of $54 \mathrm{~dB}$ and above is caused by the strong $\mathrm{AE}$ source generated by crack initiation and propagation. Table 2 is the main distribution range of the parameters of the AE signal.

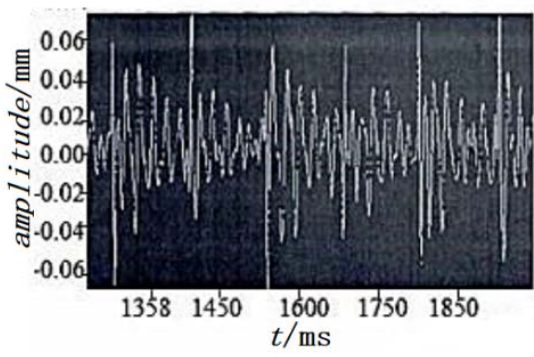

(a)oscillogram

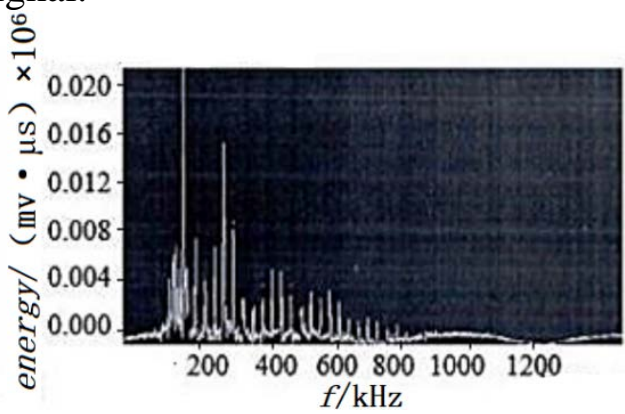

(b)spectrogram

Fig.3 The waveform and spectrogram of the AE signal on with surface crack propagation

Table 2 AE signal parameters range of surface crack propagation stage

\begin{tabular}{lcccccc}
\hline & $\begin{array}{c}\text { Amplitude } \\
(\mathrm{dB})\end{array}$ & $\begin{array}{c}\text { Energy } \\
(\mathrm{mv} \cdot \mu \mathrm{s})\end{array}$ & hits & $\begin{array}{c}\text { Lasting time } \\
(\mu \mathrm{s})\end{array}$ & $\begin{array}{c}\text { Raising time } \\
(\mu \mathrm{s})\end{array}$ & $\begin{array}{c}\text { RMS } \\
(\mathrm{dB})\end{array}$ \\
\hline distribution & $40-75$ & $0-2514$ & $1-64351$ & $0-1.1 \times 107$ & $0-2.1 \times 106$ & $1773-4503$ \\
Main range & $48-60$ & $300-14524$ & $244-37510$ & $6800-1.9 \times 10^{5}$ & $4500-1.5 \times 10^{5}$ & $2500-3300$ \\
\hline
\end{tabular}

Fig. 3 shows the waveform and spectrum of AE signals of the crack growth stage. The frequency range of AE signals is distributed within the range of $90-650 \mathrm{kHz}$, and the main frequency range is $90-130 \mathrm{kHz}$ and $108-260 \mathrm{kHz}$, The peak values of $430 \mathrm{kHz}$ and $630 \mathrm{kHz}$ are obvious, and the main energy is concentrated in the first frequency band. 


\subsection{Analysis of AE signal parameters of welding-defected Q235 specimen}

The welding defect of prefabricated specimen is located at $120 \mathrm{~mm}$.And table 3 is the statistical table of AE localization events of the specimen.

Table 3 AE positioning event statics of specimen loading process

\begin{tabular}{ccccc}
\hline Load process & loading $(\mathrm{kN})$ & Main location area(mm) & Number of events & note \\
\hline 1st & $6-10$ & $122-125$ & 3 & Focus on the defect \\
2st & $10-15$ & $122-125$ & 5 & Focus on the defect \\
3st & $15-18.5$ & - & - & - \\
\hline
\end{tabular}

It can be seen from Table 3 that the main AE location area overlapped during the first loading and the second loading, and the maximum deviation from the actual defect location was $5 \mathrm{~mm}$, less than $5 \%$ of the sensor spacing, approaching the requirements of positioning accuracy.

The characteristic parameter detected by $\mathrm{AE}$ in defect expansion processing during the loading process shows that in the low stress loading process, the signal is mainly continuous and contains a small amount of signals generated by residual stress and friction between specimen and fixture; When the load rises to the second stage, the energy rate increases to the peak value, and cracks are generated inside the welding defects and then expands.It can be seen from the course map that the $\mathrm{AE}$ of the welding defect specimen is high in amplitude, and the concentration of the AE signals is near $58 \mathrm{~dB}$, and the number of impacts is almost 1 , and the counts is mostly lower than 34000 .

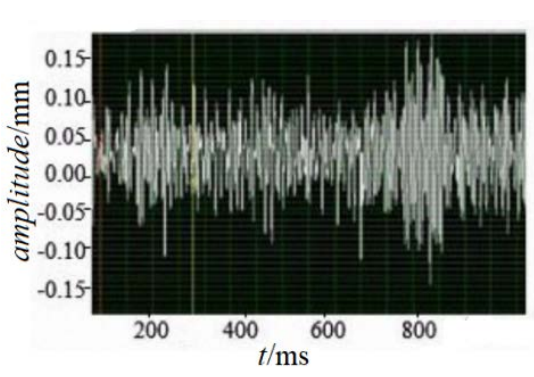

(a)Oscillogram

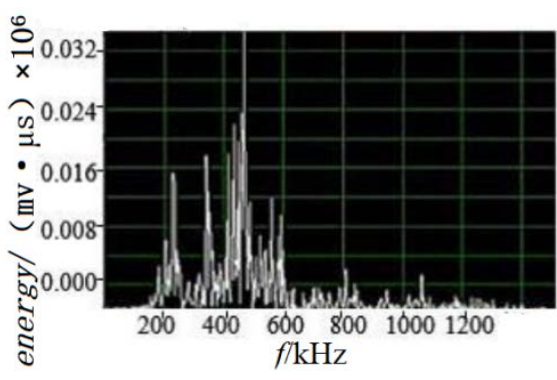

(b) Spectrogram

Fig.4 The waveform and spectrogram of the AE signal on welding defects

Fig. 4 shows the waveform and spectrum of AE signal generated by defect expansion during the loading process. The signal band range is $90-540 \mathrm{kHz}$, and the main energy distribution is in the range of $100-300 \mathrm{kHz}$, and the peak value appears near $230 \mathrm{kHz}$.Table 4 is a summary of the distribution range of main parameters of AE signal of welding defects.

Table 4 AE signal parameters range of welding defects specimen

\begin{tabular}{ccccccc}
\hline & $\begin{array}{c}\text { Amplitude } \\
(\mathrm{dB})\end{array}$ & $\begin{array}{c}\text { Energy } \\
(\mathrm{mv} \cdot \mu \mathrm{v})\end{array}$ & Hits & $\begin{array}{c}\text { Lasting time } \\
(\mu \mathrm{s})\end{array}$ & $\begin{array}{c}\text { Raising } \\
\text { time }(\mu \mathrm{s})\end{array}$ & $\begin{array}{c}\text { RMS } \\
(\mathrm{dB})\end{array}$ \\
\hline Range & $56-85$ & $521-3.8 \times 10^{6}$ & $225-65281$ & $5500-1.3 \times 10^{8}$ & $5000-1.4 \times 10^{8}$ & $3143-4877$ \\
Main range & $56-65$ & $750-2.8 \times 10^{5}$ & $750-33486$ & $1.2 \times 10^{4}-1.0 \times 10^{8}$ & $7200-5.1 \times 10^{5}$ & $3200-3600$ \\
\hline
\end{tabular}

\section{Conclusions}

(1) The analysis of characteristics of $\mathrm{AE}$ signal and the location diagram shows that: $\mathrm{AE}$ technology can realize fault localization of two conventional defects, which are crack and welding defects, and localization accuracy is within $5 \%$. 
(2)In the tensile process of cracked Q235 specimen, the frequency band of typical Hit signal distribution is within $90 \sim 130 \mathrm{kHz}$ and $180 \sim 260 \mathrm{kHz}$, and the maximum peak appears around $100 \mathrm{kHz}$.In the tensile process of welding-defected Q235 specimen, the Hit signal frequency band mainly distributed in the range of $100-300 \mathrm{khz}$ and the peak value appeared near $230 \mathrm{kHz}$. As a result, the feature identification of the two conventional defects can be realized.

\section{Acknowledgments}

The authors would like to acknowledge the financial support of the Basic Science and Research Project of Chinese National University, China (Grant No. N160304008) and the Aeronautical Science Foundation of China (Grant NO. 20170250001).

\section{References}

[1] J.Kaiser,Ph.D, Thesis, Techniche Hochschulo Munchen Munich,J, Germany, 1950.

[2] Javadi Y, Sadeghi S, Najafabadi M A, Taguchi optimization and ultrasonic measurement of residual stresses in the friction stir welding, J. Materials \& Design, 55 (2014) 27-34.

[3] SK Al-Jumaili ,MJ Eaton, Characterisation of fatigue damage in composites using an Acoustic Emission Parameter Correction Technique, J. Composites Part B: Engineering, 151 (2018) 237-244.

[4] Liu Yihua, Hu Jianfeng, Yang Huaping . Fatigue life analysis of tower mast section for tower crane,J. Construction Machinery,2 (2015) 90-92. 